CASE REPORT

\title{
A patient with insidious onset of exertional dyspnoea
}

\section{P Eller, M Lechleitner, A Gschwendtner, A Kreczy, L Müller, N Kaneider, J R Patsch}

Thorax 2005;60:437-438. doi: 10.1136/thx.2004.023622

The case history is presented of a 42 year old woman with pulmonary artery occlusion due to tuberculous vasculitis that masqueraded as chronic pulmonary artery embolism and led to severe life threatening haemoptysis necessitating emergency pneumonectomy. It is concluded that obliterative tuberculous endarteritis of the pulmonary arteries should be considered in the differential diagnosis of any acquired obstruction of pulmonary arteries.

n February 2002 a 42 year old Austrian woman with a 5 month history of progressive exertional dyspnoea and fatigue was admitted to our hospital. The diagnosis on admission was a chronic central pulmonary artery embolism based on lung perfusion scintigraphy showing complete closure of the right pulmonary artery. Physical examination revealed rales over the right lung. Routine laboratory values were in the normal range except for the D-dimer and CRP values which were slightly raised to $246 \mu \mathrm{g} / \mathrm{l}$ and $1.30 \mathrm{mg} / \mathrm{dl}$, respectively. No peripheral vein thrombosis was found upon duplex sonography, systolic pulmonary arterial pressure was within normal limits, and the electrocardiogram demonstrated bradycardia. Chest radiographs revealed a small calcified granuloma of the right apical lobe and patchy infiltrates of the right lung consistent with pneumonia.
Oral anticoagulation with acenocoumarol and antibiotic treatment with amoxycillin/clavulanate and clarithromycin were started. A computed tomographic scan performed after 9 days of medical treatment still showed complete obstruction of the proximal right pulmonary artery and a partially calcified mediastinal mass nearby. In view of a strong family history of malignancies, we considered the possibility of hilar lung carcinoma or of a leiomyosarcoma of the right pulmonary artery, which are known to mimic chronic pulmonary embolism. ${ }^{1}$ Anticoagulation treatment was stopped and the patient underwent bronchoscopy and mediastinoscopy. Multiple mediastinal lymphatic nodes were biopsied but histological analysis showed no neoplasia. Exfoliative cytology, cyfra-21-1, and neurone specific enolase were normal.

On day 26 the patient developed haemoptysis. Bronchoscopic examination showed no source of bleeding that could be treated interventionally. The patient underwent emergency pneumonectomy 3 days later for ongoing life threatening bleeding. Histological examination of the surgical specimen showed no neoplasia. The mediastinal mass adjacent to the right pulmonary artery was a sclerosed, partially calcified, partially caseous lymph node. The right pulmonary artery adjacent to the sclerosed lymph node showed occluding vasculitis (fig lA). There were dense granulomatous infiltrates of lymphocytes and plasma cells, fibroblastic proliferations, epitheloid cells, and scattered
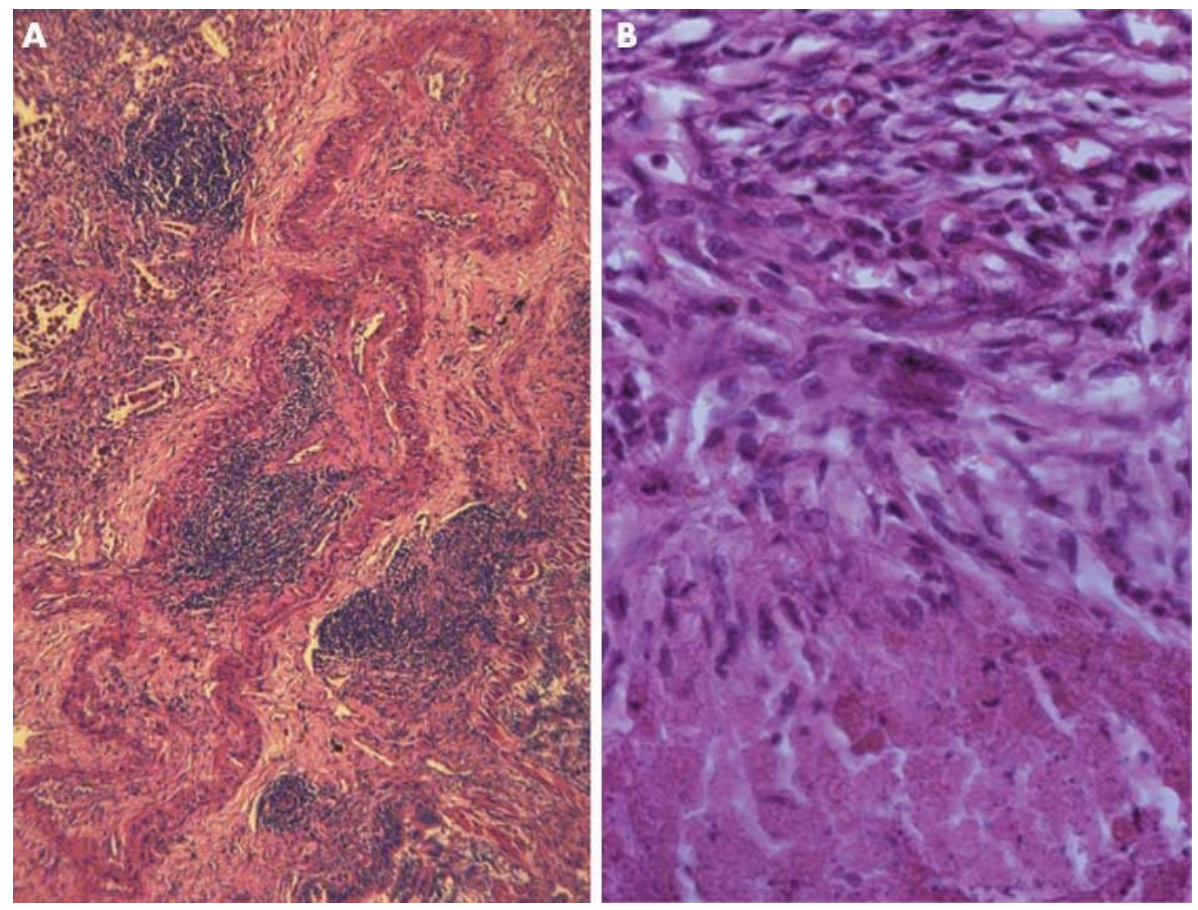

Figure 1 (A) Obliterative endarteritis of the pulmonary artery. (B) Intravascular granuloma with caseous necrosis, epitheloid cells, and a Langhans giant cell. 
Langhans giant cells (fig 1B). Ziehl-Neelsen staining did not reveal any acid-fast bacilli. However, the tuberculin skin test was positive with an induration size of $16 \mathrm{~mm}$, as well as PCR for the insertion element IS6110 of Mycobacterium tuberculosis DNA from tissue samples, which was performed as previously described by Eisenach et al. ${ }^{2}$ In the periphery of the lung, small to medium sized pulmonary vessels showed a florid panarteritis leading to infarcts with necrotic debris. There were multiple haemosiderin loaded alveolar macrophages.

We excluded the involvement of any other arteries beyond those of the right lung by $\left({ }^{18} \mathrm{~F}\right)$-fluorodeoxyglucose positron emission tomography and magnetic resonance angiography. Tests for antinuclear, antineutrophil cytoplasmic, antiglomerular basement membrane, antiphospholipid, and anticardiolipin antibodies were negative, as were serological tests for syphilis, hepatitis B, and hepatitis C. However, the patient had high titres of anti-endothelial cell antibodies which are non-specific indicators of inflammatory mediated damage to the vessel wall. ${ }^{3}$ She had not been vaccinated with bacillus Calmette-Guerin.

Our final diagnosis was that of a post-primary pulmonary tuberculosis which led to complete occlusion of the right pulmonary artery and to lung infarcts by granulomatous obliterative vasculitis. The patient made an uneventful recovery on antituberculous chemotherapy with isoniazid and rifampicin. There were no signs of disease on follow up 2 years later.

\section{DISCUSSION}

Granulomatous endarteritis of pulmonary vessels is a specific manifestation of tuberculosis that can be reproduced in experimental studies with infected guinea pigs. ${ }^{5}$ In our patient the infection seemed to have spread from the hilar caseous lymph node to the adjacent right pulmonary artery and by intravascular propagation to the small vessels of the lung periphery, thus leading to multiple pulmonary infarcts and finally to severe haemoptysis. Interestingly, our patient had high titres of anti-endothelial cell antibodies which may play a role in enhancing the vasculitis that was triggered by $M$ tuberculosis.

Previous reports on acquired stenoses of the pulmonary arteries by tuberculous mediastinal lymphadenopathy have concentrated on the mechanical compression of pulmonary vessels. $^{6-10}$ This case illustrates the extensive concomitant endarteritis of the pulmonary artery.

Obliterative tuberculous endarteritis should be considered in the differential diagnosis of any acquired obstruction of pulmonary arteries, primarily in countries with a high incidence and prevalence of tuberculosis but also in older patients originating from industrialised countries.

\section{Authors' affiliations}

P Eller, M Lechleitner, N Kaneider, J R Patsch, Department of Internal Medicine, Innsbruck University Hospital, Austria

A Gschwendtner, A Kreczy, Institute of Pathology, Innsbruck University Hospital, Austria

L Müller, Department of Cardiac Surgery, Innsbruck University Hospital, Austria

Correspondence to: Dr M Lechleitner, Department of Internal Medicine, Innsbruck University Hospital, Anichstrasse 35, 6020 Innsbruck, Austria; monika.lechleitner@uibk.ac.at

Received 22 February 2004

Accepted 22 April 2004

\section{REFERENCES}

1 Burke AP, Virmani R. Sarcomas of the great vessels. A clinicopathologic study. Cancer 1993;71:1761-73

2 Eisenach KD, Cave MD, Bates JH, et al. Polymerase chain reaction amplification of a repetitive DNA sequence specific for Mycobacterium tuberculosis. J Infect Dis 1990;161:977-81.

3 Belzina C, Tervaert JW. Specificity, pathogenicity, and clinical value of antiendothelial cell antibodies. Semin Arthritis Rheum 1997;27:98-109

4 Prapotnik S, Blank M, Meronie PL, et al. Classification of anti-endothelial cell antibodies against microvascular and macrovascular endothelial cells: the pathogenic and diagnostic implications. Arthritis Rheum 2001;44:1484-94.

5 Pagel W, Henke F. Lungentuberkulose. Veränderungen an den Gefäßen. Handbuch der spezifischen pathologischen Anatomie und Histologie. Berlin: Springer, 1930

6 Gough JH, Gold RG, Gibson RV. Acquired pulmonary stenosis and pulmonary artery compression. Thorax 1967;22:358-67.

7 Drake WM, Elkin SL, al-Kutoubi A, et al. Pulmonary artery occlusion by tuberculous mediastinal lymphadenopathy. Thorax 1997;52:301-2.

8 Palevsky HI, Cone L, Alavi A. A case of false-positive high probability ventilation-perfusion lung scan due to tuberculous mediastinal adenopathy with a discussion of other causes of false-positive high probability ventilationperfusion lung scans. J Nucl Med 1991;32:512-7.

9 Equi A, Redington A, Rosenthal $M$, et al. Pulmonary artery occlusion from tuberculous lymphadenopathy. Pediatr Pulmonol 2001;31:311-3.

10 Cohen AS, Beaconsfield T, al-Koutobi A, et al. Pulmonary artery reconstruction for tuberculosis. Ann Thorac Surg 1996;61:1257-9. 